\title{
Esophageal intramural pseudodiverticulosis associated with achalasia: an unusual endoscopic appearance
}

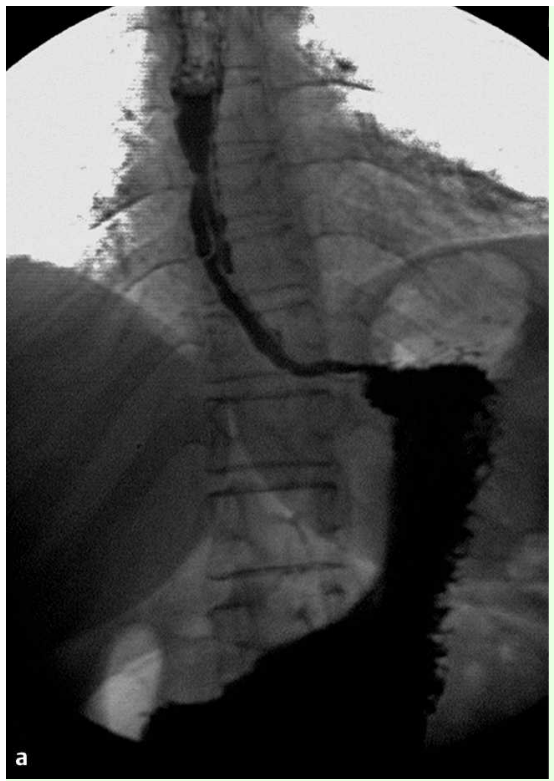

Fig. 1 a Barium esophagogram showing intramural tracks parallel to the long axis of the esophagus. b Esophageal manometry tracing shows simultaneous peristalsis with partial relaxation of the lower esophageal sphincter.

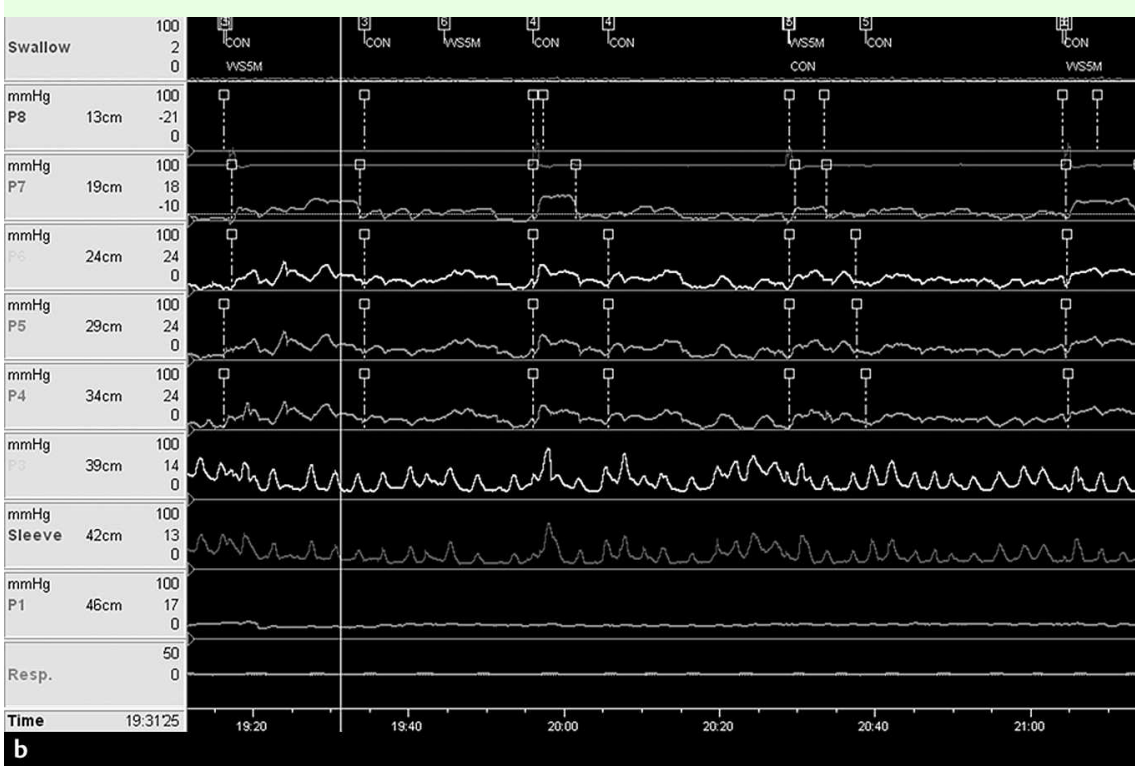

A 45-year-old woman was admitted to our hospital because of progressive dysphagia, especially in relation to solid foods, that had lasted for 3 years. A barium esophagogram revealed long intramural collections extending parallel to the long axis of the esophageal lumen with delayed emptying from the esophagus ( $\odot$ Fig. 1 a). Upper endoscopy showed multiple orifices of pseudodiverticula of different sizes and the surface had a "Swiss cheese" appearance, with some of the "holes" being grouped to form a honeycomb pattern in mid esophagus (- Fig. 2 and Video 1). No web or stricture was seen. The biopsy specimens obtained from the edges of the pseudodiverticula revealed nonspecific esophagitis without evidence of candidal infection. Esophageal manometry using a Dent sleeve catheter demonstrated simultaneous low-amplitude peristalsis in the esophageal body and incomplete lower esophageal sphincter relaxation in re-

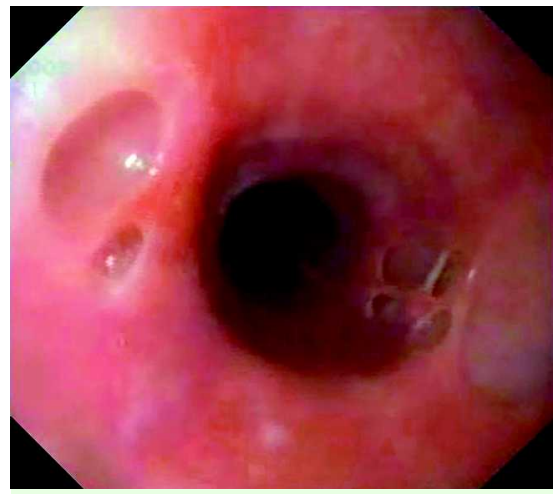

Fig. 2 Upper endoscopy showing multiple orifices of pseudodiverticula of different sizes; some of the "holes" have grouped to form a pattern in mid esophagus.

sponse to wet swallows, suggesting a diagnosis of achalasia ( $\bullet$ Fig. 1 b). The patient was treated for achalasia with endoscopic esophageal injection of botulinum toxin type A. Symptoms improved and she was well for 1.5 years, but was subsequently readmitted to the hospital for recurrent dysphagia. Endoscopy again showed the same findings. A repeat injection of botulinum toxin was given and the patient's symptoms resolved. She was discharged and advised to return if symptoms recurred.

Esophageal intramural pseudodiverticulosis (EIPD) is a rare entity of unknown etiology in which excretory ducts of submucosal esophageal mucous glands become dilated, forming tiny outpouchings or pseudodiverticula. There can be areas of tracking where communicating channels occur between pseudodiverticula [1], as in our patient. Conditions associated with EIPD include a history of caustic ingestion, chronic alcoholism, gastroesophageal reflux disease, web, diabetes, candidal esophagitis, esophageal carcinoma, and strictures [2]. All were absent in our patient. Therefore, it appears reason-

\section{Video 1}

Endoscopic appearance of the esophageal lumen in a case of esophageal intramural pseudodiverticulosis associated with achalasia. 
able to assume that the EIPD was related to the achalasia in this case, or that these intramural pseudodiverticula disrupted the neural pathways within the esophageal wall, giving a similar clinical picture to achalasia. Esophageal motility disorders have been described in association with EIPD $[3,4]$. In our review of the literature, we found only one previously reported case of EIPD associated with achalasia, which was treated by balloon dilation [3]. Although the diverticula of patients with EIPD are usually small (1$5 \mathrm{~mm}$ in diameter), two cases of multiple large pseudodiverticula (up to $15 \mathrm{~mm}$ ) have been reported [5]. An unusual appearance, however, was observed in our patient. We consider that this condition may be related to the underlying dysmotility.

Endoscopy_UCTN_Code_CCL_1AB_2AC_3AF

Endoscopy_UCTN_Code_CCL_1AB_2AC_3AH
I. Turan, E. Ozen, S. Bor, O. Ozutemiz

Section of Gastroenterology, Ege Uni-

versity School of Medicine, Izmir, Turkey

\section{References}

1 Canon CL, Levine MS, Cherukuri R et al. Intramural tracking: a feature of esophageal intramural pseudodiverticulosis. Am J Roentgenol 2000; 175: $371-374$

2 Jeyarajah $R$, Harford $W$. Diverticula of the hypopharynx, esophagus, stomach, jejunum, and ileum. In: Feldman M, Friedman LS, Sleisenger MH (eds). Sleisenger \& Fordtran's Gastrointestinal and liver disease: pathophysiology, diagnosis, management. Philadelphia: Saunders, 2002: 359-368

3 Dua KS, Stewart E, Arndorfer R et al. Esophageal intramural pseudodiverticulosis associated with achalasia. Am J Gastroenterol 1996; 91: 1859- 1860

4 Walker S, Hippeli R, Goes R. Diffuse esophageal intramural pseudodiverticulosis and nutcracker esophagus in a 54 year old man. Klin Wochenschr 1990; 68: 187-190

5 Herter B, Dittler HJ, Wuttge-Hanning A et al. Intramural pseudodiverticulosis of the esophagus: a case series. Endoscopy 1997; 29: $109-113$
Bibliography

DOI $10.1055 / \mathrm{s}-0028-1103473$

Endoscopy 2009; 41: E23 -E24

(c) Georg Thieme Verlag KG Stuttgart · New York . ISSN 0013-726X

Corresponding author

\section{Turan, MD}

Ege Universitesi Tip Fakultesi

Gastroenteroloji Bilim Dali

Bornova 35100

Izmir

Turkey

Fax: +90-232-3731547

ilkerturan@gmail.com 